\title{
Self-Rated Cardiovascular Risk and 15-Year Cardiovascular Mortality
}

Robert Gramling, MD, DSc $\mathrm{c}^{1,2,3}$

William Klein, $\mathrm{PbD}^{4}$

Mary Roberts, $M S^{1}$

Molly E. Waring, MS $S^{1,3}$

David Gramling, $\mathrm{PbD}^{5}$

Charles B. Eaton, MD, MS $S^{1,2}$

${ }^{1}$ Center for Primary Care and Prevention, Memorial Hospital of Rhode Island, Pawtucket

${ }^{2}$ Department of Family Medicine, Warren Alpert Medical School of Brown University, Providence, Rhode Island

${ }^{3}$ Department of Community Health, Warren Alpert Medical School of Brown University, Providence, Rhode Island

${ }^{4}$ Department of Psychology, University of Pittsburgh, Pittsburgh, Pennsylvania

${ }^{5}$ Department of German, University of California, Berkeley

\begin{abstract}
PURPOSE Many individuals perceive their cardiovascular disease (CVD) risk to be lower than established clinical tools would estimate, yet little is known about the long-term consequences of holding such optimistic beliefs. We evaluated whether lower self-ratings of CVD risk are associated with lower rates of CVD death after addressing potential confounding by an extensive set of social and biologic CVD risk factors.
\end{abstract}

METHODS We conducted a 15-year mortality surveillance study of adults aged 35 to 75 years from southeastern New England $(n=2,816)$ who had no history of myocardial infarction. Baseline evaluation in 1990-1992 included household interview, anthropomorphic measures, and laboratory analyses. Outcomes were obtained using the National Death Index records through December 2005.

RESULTS Rating oneself to be at lower-than-average risk for one's age and sex was associated with lower rates of CVD mortality among men (hazard ratio $[\mathrm{HR}]=0.3 ; 95 \%$ confidence interval $[\mathrm{Cl}], 0.2-0.7)$ but not among women $(\mathrm{HR}=0.9 ; 95 \% \mathrm{Cl}, 0.5-1.7)$. None of the following weakened the findings among men: adjustment for baseline Framingham Risk Score, propensity score adjustment for both social and biologic factors, and censoring the first 2 years of surveillance.

CONCLUSIONS Lower self-ratings of CVD risk are independently associated with lower rates of CVD death among men.

Ann Fam Med 2008;6:302-306. DOI: 10.1370/afm.859.

\section{INTRODUCTION}

$\mathrm{R}$ isk perception affects health behavior and emotional well-being among individuals facing a health threat. ${ }^{1-3}$ When the behavior required to ameliorate the threat is a single event (eg, vaccination), ${ }^{4}$ heightened perceptions of risk appear to motivate preventive action. In turn, successful completion of the preventive action facilitates reduction in risk perception. ${ }^{4}$ Thus, holding higher risk perceptions can be beneficial in some health contexts.

The threat of cardiovascular disease (CVD), however, requires preventive actions that are not single events; they are multidimensional, ongoing, and effort-intensive. The preventive value of harboring higher perceptions of CVD risk is therefore less clear. An individual's failure to engage and sustain CVD preventive action can exacerbate negative emotions arising from threat perception, thereby leading to dysfunctional coping behaviors. In fact, holding optimistic perceptions of risk, whether through lack of awareness or denial, may protect against fear-related coping behaviors and the physiologic effects of stress that, in turn, can hasten the onset of CVD events. ${ }^{5.7}$ These benefits might explain why so many adults tend to underestimate their personal risk of experiencing a CVD event. ${ }^{8-12}$

Given the rapid emergence of genetic technologies that are likely to shape risk perceptions ${ }_{1}{ }^{13}$ it is both timely and essential to investigate the long-term health impact of self-rated risk. We conducted a 15 -year mor- 
tality surveillance study of adults who rated their own CVD risk in the early 1990s, hypothesizing that lower self-rated risk would be associated with lower rates of CVD death.

\section{METHODS}

\section{Study Population}

We obtained mortality data through December 2005 for 2,816 adults who completed household interviews between 1990 and 1992 as part of the Pawtucket Heart Health Program. Eligibility criteria included completion of a household interview, provision of a blood sample for cholesterol measurement, no history of myocardial infarction, and an age of 35 years or older.

\section{Measures}

Participants were asked the following question at the beginning of the household interview: "Compared with persons of your own age and sex, how would you rate your risk of having a heart attack or stroke within the next 5 years?" Participants rated their cardiovascular risk as "high," "average," "low," or "don't know." Comparative risk perceptions often better reflect how people think about risk than do absolute risk perceptions, in part because it is easier to compare oneself with others than it is to accurately estimate one's absolute risk. ${ }^{14}$ Experimental studies manipulating both absolute and comparative risk feedback often find a stronger effect of the comparative feedback on emotion and behavior, ${ }^{15,16}$ and measures such as the one used here are reliable. ${ }^{17}$

We obtained mortality outcomes, including date and cause of death, by linking personal identifiers for each participant to public use data from the Centers for Disease Control and Prevention National Death Index (NDI) for the years 1990-2005. Matching was facilitated by an NDI-standardized threshold for determining agreement between the submitted personal identifiers and those in the NDI record. Participants not found to have died were considered to have completed the surveillance period alive. CVD death was defined as death due to coronary heart disease or stroke based upon the International Classification of Disease (ICD) coding for the underlying or contributing cause of death (ICD-9: 410-414, 430-438; ICD-10: $120-125,160-169)$. Data on individuals dying from other causes were censored at the time of death.

The following variables were considered for potential confounding: age, sex, city of residence, race/ ethnicity, income, education, foreign birth, total/highdensity lipoprotein (HDL) cholesterol ratio, blood pressure, smoking status, obesity, first-degree family history of early-onset coronary heart disease, and current use of lipid-lowering agents, antihypertensive medications, and hormone replacement therapy. All medication bottles were confirmed by the household interviewer and cross-checked with pharmacy records.

\section{Analysis}

All analyses were stratified by sex. We calculated frequency and distribution of each study variable. We assessed the crude association between low self-rated CVD risk and CVD-related mortality using a Cox proportional hazards model.

The most compelling potential confounder of this relation is a person's actual CVD risk at baseline. Consequently, we approached confounding by 3 methods. First, we included categorical variables in our hazards model for the Framingham Risk Score ${ }^{18,19}$ categories that are based on age, sex, blood pressure, smoking status, total cholesterol, and HDL cholesterol. Next, we conducted propensity score analyse ${ }^{20}$ designed to eliminate the association between a large set of potential confounders and a nonrandomized exposure, in our case low self-rated CVD risk. Finally, to address the potential impact of unmeasured confounding by other life-threatening disease, we duplicated the analysis eliminating the first 2 years of surveillance.

This study was approved by the Memorial Hospital of Rhode Island Committee on the Use of Human Subjects in Research.

\section{RESULTS}

The characteristics of our study sample by sex and low self-rated CVD risk are displayed in Table 1. Approximately one-half were under the age of 55 years, the great majority was white, and nearly one-half did not complete high school. During the 15 -year surveillance period, we identified 281 deaths (139 among the 1,678 women and 142 among the 1,138 men). Ninety-eight deaths were either due to coronary heart disease $(\mathrm{n}=81)$ or stroke $(\mathrm{n}=17)$.

We observed that men who rated their CVD risk to be lower than men of their same age had nearly a 3 times lower incidence of CVD-related mortality compared with all others in both crude and Framingham Risk Score adjusted analyses (Table 2). Neither propensity score adjustment (adjusted hazard ratio $\left[\mathrm{HR}_{\mathrm{adj}}\right]=0.4 ; 95 \%$ confidence interval $\left.[\mathrm{CI}], 0.2-0.8\right)$ nor censoring the first 2 years of surveillance altered these findings $\left(\mathrm{HR}_{\mathrm{adj}}=0.4 ; 95 \% \mathrm{CI}, 0.2-0.9\right)$. The relation was not dose-dependent across strata of self-rated CVD risk.

Among women, we observed a null crude association (Table 2). The association showed a weak but potentially opposite direction than that for men when adjusting for Framingham Risk Score or propensity score $\left(\mathrm{HR}_{\mathrm{adj}}=1.5\right.$; $95 \% \mathrm{CI}, 0.8-2.8)$ that persisted after censoring the first 


\begin{tabular}{|c|c|c|c|c|c|c|}
\hline \multirow[b]{2}{*}{ Characteristic } & \multicolumn{3}{|c|}{ Women "Lower Than Average" } & \multicolumn{3}{|c|}{ Men "Lower Than Average" } \\
\hline & $\begin{array}{c}\text { Yes } \\
\text { n }(\%)^{a}\end{array}$ & $\begin{array}{c}\text { No } \\
\text { n (\%) }\end{array}$ & $P$ Value $^{\mathrm{b}}$ & $\begin{array}{c}\text { Yes } \\
\text { n (\%) }\end{array}$ & $\begin{array}{c}\text { No } \\
\text { n }(\%)^{a}\end{array}$ & $P$ Value $^{b}$ \\
\hline Total & $557(33)$ & $1,121(67)$ & & $397(35)$ & $741(65)$ & \\
\hline Age at enrollment & & & $<.01$ & & & .28 \\
\hline $35-44$ y & $209(38)$ & $322(29)$ & & $141(36)$ & $247(33)$ & \\
\hline $45-54$ y & $142(26)$ & $288(26)$ & & $98(25)$ & $210(28)$ & \\
\hline $55-64$ y & $111(20)$ & $299(27)$ & & $89(22)$ & $179(24)$ & \\
\hline $65-75$ y & $95(17)$ & $212(19)$ & & $69(17)$ & $104(14)$ & \\
\hline Race/ethnicity & & & .22 & & & .29 \\
\hline White, non-Hispanic & $503(90)$ & 977 (87) & & $357(90)$ & $664(90)$ & \\
\hline White, Hispanic & $8(1.4)$ & $17(1.5)$ & & $3(0.8)$ & $10(1.3)$ & \\
\hline Black/African American & $14(2.5)$ & $31(2.8)$ & & $16(4.0)$ & $18(2.4)$ & \\
\hline Other & $32(5.7)$ & $96(8.6)$ & & $21(5.3)$ & $49(6.6)$ & \\
\hline Education level & & & $<.01$ & & & .01 \\
\hline$<$ High school graduate & $197(35)$ & $543(48)$ & & $163(41)$ & $374(51)$ & \\
\hline High school graduate & $167(30)$ & $321(29)$ & & $94(24)$ & $167(23)$ & \\
\hline Some college & $107(19)$ & $171(15)$ & & $77(19)$ & $110(15)$ & \\
\hline z4-y college graduate & $86(15)$ & $86(7.7)$ & & $63(16)$ & $90(12)$ & \\
\hline Per capita household income & & & $<.01$ & & & .01 \\
\hline$<\$ 7,500$ & $200(36)$ & $515(46)$ & & $117(30)$ & $268(36)$ & \\
\hline$\$ 7,500$ to $<\$ 12,500$ & $146(26)$ & $266(24)$ & & $95(24)$ & $195(26)$ & \\
\hline$>\$ 12,500$ & $211(38)$ & $340(30)$ & & $185(47)$ & $278(38)$ & \\
\hline Foreign born & $132(24)$ & $348(31)$ & $<.01$ & $115(29)$ & $268(36)$ & .01 \\
\hline Family historyc & $40(10)$ & $91(12)$ & .11 & $73(13)$ & $181(16)$ & .27 \\
\hline Current smoker & $110(20)$ & $308(28)$ & $<.01$ & $92(23)$ & $274(37)$ & $<.01$ \\
\hline Obese & $94(17)$ & $400(36)$ & $<.01$ & $81(20)$ & $205(28)$ & $<.01$ \\
\hline Diabetes mellitus ${ }^{d}$ & $29(5.2)$ & $115(10)$ & $<.01$ & $27(6.8)$ & $71(9.6)$ & .11 \\
\hline Hypertensione & $156(28)$ & $489(44)$ & $<.01$ & $169(43)$ & $365(49)$ & .03 \\
\hline Total cholesterol >200 mg/dL & $331(59)$ & $813(73)$ & $<.01$ & $264(67)$ & $551(74)$ & $<.01$ \\
\hline
\end{tabular}

2 years of surveillance $\left(\mathrm{HR}_{\mathrm{adj}}=1.7 ;\right.$ 95\% CI, 0.8-3.3).

Low self-rated CVD risk was more frequently associated with known risk factors among women than men (Table 1). Forty-five percent of men with low selfrated CVD risk were categorized as having high or very high levels of risk based upon the Framingham Risk Score, whereas only 9\% of women were categorized as having high or very high levels of risk (Table 3 ).

\section{DISCUSSION}

Our findings suggest that men who self-rate their CVD risk lower than average have better outcomes as measured by rates of CVD death. The data support
Table 2. Crude and Framingham Risk Score-Adjusted Association Between Low Self-Rated CVD Risk and CVD Death by Sex

\begin{tabular}{|c|c|c|c|c|c|c|}
\hline \multirow[b]{2}{*}{$\begin{array}{l}\text { Low } \\
\text { SRR }\end{array}$} & \multicolumn{3}{|c|}{ Women $(n=1,678)$} & \multicolumn{3}{|c|}{ Men $(n=1,138)$} \\
\hline & $\begin{array}{c}\text { No. of } \\
\text { Deaths } \\
\text { From CVD }\end{array}$ & $\begin{array}{c}\text { HR } \\
(95 \% \mathrm{Cl})\end{array}$ & $\begin{array}{c}\mathrm{HR}_{\text {adj }} \\
(95 \% \mathrm{Cl})\end{array}$ & $\begin{array}{c}\text { No. of } \\
\text { Deaths } \\
\text { From CVD }\end{array}$ & $\begin{array}{c}\text { HR } \\
(95 \% \mathrm{Cl})\end{array}$ & $\begin{array}{c}\text { HR }_{\text {adj }} \\
(95 \% \mathrm{Cl})\end{array}$ \\
\hline Yes & 14 & $\begin{array}{c}0.9 \\
(0.5-1.7)\end{array}$ & $\begin{array}{c}1.5 \\
(0.8-2.8)\end{array}$ & 8 & $\begin{array}{c}0.3 \\
(0.2-0.7)\end{array}$ & $\begin{array}{c}0.4 \\
(0.2-0.8)\end{array}$ \\
\hline No & 30 & ref & ref & 46 & ref & ref \\
\hline
\end{tabular}

$\mathrm{Cl}=$ confidence interval; $\mathrm{CVD}=$ cardiovascular disease; $\mathrm{HR}=$ hazard ratio; $\mathrm{HR}_{\mathrm{adj}}=$ adjusted hazard ratio; ref $=$ reference group; SSR = self-rated cardiovascular disese risk. 


\begin{tabular}{|c|c|c|}
\hline Distribution & $\begin{array}{c}\text { Women } \\
(n=555) \\
\%\end{array}$ & $\begin{array}{c}\text { Men } \\
(\mathrm{n}=396) \\
\%\end{array}$ \\
\hline Low ( $<2$ risk factors and $<10 \% 10-y$ risk) & 75.0 & 46.0 \\
\hline Moderate ( $>2$ risk factors and $<10 \% 10-y$ risk) & 16.0 & 9.3 \\
\hline High (10\%-20\% 10-y risk) & 4.1 & 19.0 \\
\hline Very high (>20\% 10-y risk) & 5.2 & 26.0 \\
\hline
\end{tabular}

self-rated their baseline risk to be lower than average were far less accurate than women. Prior work consistently finds that self-rated CVD risk appears optimistically biased when compared with state-of-the-art epidemiologic models. ${ }^{8-10,21,22}$ These observations lend compelling evidence that our findings are not merely a result of confounding by one's objective baseline risk, but rather a prism of postbaseline phenomena. The current study indicates that holding optimistic perceptions of risk leads to advantages, at least for men.

There are plausible behavioral explanations for our findings. The Extended Parallel Process Model ${ }^{23}$ posits that higher perceptions of risk for such dreaded events as heart attack or stroke cause a fear response, and the intensity and duration of that fear are mitigated by one's beliefs about the capacity to prevent such events from happening. Until a certain critical point - a heuristic representing the degree of fear and the perceived capacity to ameliorate the risk - the individual will try to prevent CVD (threat control) to lower his or her fear. A failed attempt to engage in or sustain CVD risk-reducing behaviors, however, exacerbates initial levels of fear. Once the critical point is reached, the individual engages fear-control processes to preserve psychological well-being (ie, denial of risk, overeating, smoking).

Our data support 2 inferences related to the Extended Parallel Process Model. The first is that men, on average, have reached the critical point where holding higher risk perceptions is not counterbalanced by confidence in their capacity to lower CVD risk. This study represents a low-income population with relatively scarce resources for preventing CVD (ie, leisure time, structural environments supporting exercise, access to health care and medication), and such contexts can lead to lower levels of self-efficacy. ${ }^{2,24-26}$

The second inference is that endorsing a level of CVD risk which is lower than one's peers is beneficial to men, but not to women. At the time of the initial interviews in 1990-1991, heart disease was widely represented in public discourse to be primarily a health threat to men. ${ }^{27}$ We propose that women's perceptions of absolute CVD risk were so disproportionately low that expressing one's risk as equal to or higher than one's same-sex peers was still a less palpable threat to women in 1991 than to men. In fact, after adjusting for baseline CVD risk factors, holding higher levels of self-rated CVD risk appeared more beneficial, thus suggesting that the ambient level of threat for women at that historical moment was below the critical point mentioned above.

Findings of prior research evaluating the relation between self-ratings of CVD risk and CVD outcomes are consistent with our findings among men. McKenney et $\mathrm{al}^{28}$ observed that men reporting their CVD risk to be lower than average were one-half as likely to experience a CVD event. Related work also observes that global dispositional optimism, or general positive expectancies for one's future, coincides with lower rates of death from CVD. ${ }^{29}$

Among women, both McKenney et $\mathrm{al}^{28}$ and Eaker et $\mathrm{al}^{30}$ observed that women endorsing their CVD risk to be higher than average were less likely to experience a CVD event. Neither study, however, addressed potential confounding by family history or preexisting CVD. Because adjustment in our study had substantial effects on hazard estimates among women, residual confounding is an important limitation of earlier findings among women.

The current study has important limitations. First, it is likely that some participants were lost to attrition by moving outside of the National Death Index catchment area (ie, beyond the United States) or by changing their surname. The Pawtucket Heart Health Program sites were chosen for their low attrition rates, and only persons older than 35 years were included in this study, thus limiting the frequency of marriage-related name changes. Any bias resulting from these 2 factors is likely nondifferential and independent, and they would thus bias our results toward the null. Second, self-rated CVD risk can change with time. Any change should lead to a dilution of effect, as well as bias our findings toward the null. Our findings suggest that either self-rated CVD risk is somewhat stable or that the magnitude of protective effects resulting from a lower self-rated CVD risk is even larger than that observed.

Third, participants were asked to rate their risk of having a "heart attack or a stroke." Although this expression captures the major CVD events, it does not distinguish event type, thus leaving us unable to determine which perceived risk was the driving force behind the associations we observed. Lastly, we do not have data on the interval between baseline assessment and death, thereby precluding evaluation of the intermediating mechanisms. 
Our observations, if supported by further theorybased research, are of critical relevance to primary care. An implicit or explicit message about CVD risk from one's trusted physician is likely to have more enduring effects on patients' self-ratings of CVD risk than those from less-trusted sources. ${ }^{1}$ Clinicians tend to prefer normative language when communicating risk (ie, normal, high) ${ }^{31}$ that follows clinical risk-stratification schemata. Such models frequently place disproportionate numbers of patients into high-risk groups, ${ }^{32}$ thus leading to a potential for pessimistically biased CVD risk messages in clinical practice. As our capacity to characterize premorbid CVD risk (eg, predictive genetics, advanced imaging) continues to proliferate in preventive care settings, a deeper awareness of the underpinnings of optimistically-biased risk perception is urgently needed.

To read or post commentaries in response to this article, see it online at http://www.annfammed.org/cgi/content/full/6/4/302.

Key words: Fear; health knowledge, attitudes, practice; denial; risk reduction behavior; cardiovascular diseases; social psychology

Submitted October 2, 2007; submitted, revised, January 23, 2008; accepted February 12, 2008.

\section{References}

1. DiClemente RJ, Crosby RA, Kegler MC. Emerging Theories in Health Promotion Practice and Research. San Francisco, CA: Jossey-Bass; 2002.

2. Glanz K, Rimer B, Lewis FM. Health Behavior and Health Education: Theory, Research and Practice. 3rd ed. San Francisco, CA: Jossey Bass; 2002.

3. Sulls J, Wallston KA, eds. Social Psychological Foundations of Health and Illness. Malden, MA: Blackwell Publishing; 2003. Tennen $\mathrm{H}$ Affleck G, eds. Health Psychology and Behavioral Medicine.

4. Brewer NT, Weinstein ND, Cuite CL, Herrington JE. Risk perceptions and their relation to risk behavior. Ann Behav Med. 2004;27(2):125-130.

5. Labarthe D. Epidemiology and Prevention of Cardiovascular Disease: A Global Challenge. Gaithersberg, MD: Aspen; 1998.

6. Kubzansky LD, Kawachi I, Spiro A III, Weiss ST, Vokonas PS, Sparrow D. Is worrying bad for your heart? A prospective study of worry and coronary heart disease in the Normative Aging Study. Circulation. 1997;95(4):818-824.

7. Berkman LF, Kawachi I. Social Epidemiology. New York: Oxford University Press; 2000.

8. Lee C. Perceptions of immunity to disease in adult smokers. J Behav Med. 1989;12(3):267-277.

9. Niknian M, McKinlay SM, Rakowski W, Carleton RA. A comparison of perceived and objective CVD risk in a general population. Am J Public Health. 1989;79(12):1653-1654.

10. Pierce DK, Connor SL, Sexton G, Calvin L, Connor WE, Matarazzo JD. Knowledge of and attitudes toward coronary heart disease and nutrition in Oregon families. Prev Med. 1984;13(4):390-395.

11. Avis NE, Smith KW, McKinlay JB. Accuracy of perceptions of heart attack risk: what influences perceptions and can they be changed? Am J Public Health. 1989;79(12):1608-1612.
12. Green JS, Grant M, Hill KL, Brizzolara J, Belmont B. Heart disease risk perception in college men and women. J Am Coll Health. 2003;51(5):207-211.

13. Marteau TM, Roberts S, LaRusse S, Green RC. Predictive genetic testing for Alzheimer's disease: impact upon risk perception. Risk Anal. 2005;25(2):397-404.

14. Klein WM, Stefanek ME. Cancer risk elicitation and communication: lessons from the psychology of risk perception. CA Cancer J Clin. 2007;57(3):147-167.

15. Klein WM. Objective standards are not enough: affective, self-evaluative, and behavioral responses to social comparison information. J Pers Soc Psychol. 1997;72(4):763-774.

16. Klein WM. Effects of objective feedback and "single other" or "average other" social comparison feedback on performance judgments and helping behavior. Pers Soc Psychol Bull. 2003;29(3):418-429.

17. Shepperd JA, Helweg-Larsen M, Ortega L. Are comparative risk judgements consistent across time and events? Pers Soc Psychol Bull. 2003;29(9):1169-1180.

18. National Institutes of Health. Framingham Point Score. Vol 01-3305. Bethesda, MD: NIH; 2001.

19. Executive Summary of The Third Report of The National Cholesterol Education Program (NCEP) Expert Panel on Detection. Evaluation, And Treatment of High Blood Cholesterol In Adults (Adult Treatment Panel III). JAMA. 2001;285(19):2486-2497.

20. D'Agostino RB Jr. Propensity score methods for bias reduction in the comparison of a treatment to a non-randomized control group. Stat Med. 1998;17(19):2265-2281.

21. Kok FJ, Matroos AW, van den Ban AW, Hautvast JG. Characteristics of individuals with multiple behavioral risk factors for coronary heart disease: the Netherlands. Am J Public Health. 1982;72(9):986-991.

22. van Maarle MC, Stouthard ME, Bonsel GJ. Risk perception of participants in a family-based genetic screening program on familial hypercholesterolemia. Am J Med Genet A. 2003;116(2):136-143.

23. Witte K, Cameron KA, McKeon JK, Berkowitz JM. Predicting risk behaviors: development and validation of a diagnostic scale. J Health Commun. 1996;1(4):317-341.

24. Bandura A. Self-efficacy: toward a unifying theory of behavioral change. Psychol Rev. 1977;84(2):191-215.

25. Bandura A. Self-efficacy mechanism in human agency. Am Psychol. 1982;37(2):122-147

26. Bandura A. Self-efficacy: The Exercise of Control. New York, NY: Free man; 1997.

27. Hammond J, Salamonson Y, Davidson P, Everett B, Andrew S. Why do women underestimate the risk of cardiac disease? A literature review. Aust Crit Care. 2007;20(2):53-59.

28. McKenney JL, Lapane KL, Assaf AR, Carleton RA. The association between perceived risk and actual cardiovascular disease. Epidemiology. 1995;6(6):612-616.

29. Giltay EJ, Kamphuis MH, Kalmijn S, Zitman FG, Kromhout D. Dispositional optimism and the risk of cardiovascular death: the Zutphen Elderly Study. Arch Intern Med. 2006;166(4):431-436.

30. Eaker ED, Pinsky J, Castelli WP. Myocardial infarction and coronary death among women: psychosocial predictors from a 20-year follow-up of women in the Framingham Study. Am J Epidemiol. 1992;135(8):854-864.

31. Gramling R, Irvin JE, Nash J, Sciamanna C, Culpepper L. Numeracy and medicine: key family physician attitudes about communicating probability with patients. J Am Board Fam Pract. 2004;17(6):473.

32. Getz L, Sigurdsson JA, Hetlevik I, Kirkengen AL, Romundstad S, Holmen J. Estimating the high risk group for cardiovascular disease in the Norwegian HUNT 2 population according to the 2003 European guidelines: modelling study. BMJ. 2005;331(7516):551. 